\title{
Proceeding
}

11th World Congress of Performance Analysis of Sport, 16-18 November 2016. International Society of Performance Analysis of Sport. Alicante, Spain

\section{Muscular activation in rumba bolero in elite dancers of DanceSport}

\author{
ENCARNACIÓN LIÉBANA GIMÉNEZ \, ESTHER BLASCO HERRAIZ, CRISTINA MONLEÓN GARCÍA, \\ CARLOS PABLOS ABELLA, CONSUELO MORATAL LULL
}

Catholic University of Valencia San Vicente Mártir, Valencia, Spain

\begin{abstract}
Dance is beneficial sport but aren't subjected to many studies. The dancers prepare themselves physically for hours for the competitions. And the result they can be physical problems. In this case we have analysed the DanceSport, which is composed of two modalities, Standard and Latin dances. In this study, we focus on the Latin dances specifically in the rhythm of Rumba Bolero with the aim of trying to identify possible gender differences. For it in this study, we have measured by means of electromyography of surface muscles involved in the low member, during the accomplishment of a ruled choreography of Rumba Bolero. The sample was sixteen people (age between $20.50 \pm 2.75$ years) of elite DanceSport dancers. Differences between genders were found. For this reason, a different physical training between genders should be done, as well as to study if in the rest of the dances we would obtain this result. Key words: ELECTROMYOGRAPHY, MUSCULAR ACTIVATION, DANCESPORT, DANCE, GENDER.
\end{abstract}

\section{Cite this article as:}

Liébana Giménez, E., Blasco Herraiz, E., Monleón García, C., Pablos Abella, C., \& Moratal Lull, C. (2017). Muscular activation in rumba bolero in elite dancers of DanceSport. Journal of Human Sport and Exercise, 12(3proc), S807-S812. doi:https://doi.org/10.14198/jhse.2017.12.Proc3.04

Corresponding author. Escuela de Doctorado de la Universidad Católica de Valencia San Vicente Mártir, Valencia, España. http://orcid.org/0000-0002-2617-4549

E-mail: encarnacion.liebana@ucv.es

11th World Congress of Performance Analysis of Sport, 16-18 November 2016. International Society of Performance Analysis of Sport. Alicante, Spain.

JOURNAL OF HUMAN SPORT \& EXERCISE ISSN 1988-5202

(c) Faculty of Education. University of Alicante doi:10.14198/jhse.2017.12.Proc3.04 


\section{INTRODUCTION}

The dance is an excellent way of practising beneficial sport, for the health, since they work physiological necessary aspects for end was taking this activity, the dancers need to train the cardiovascular capacity, muscular flexibility, muscular strength (Malkogeorgos, Zaggelidou, Zaggelidis, \& Christos, 2013). DanceSport is the competitive form of ballroom dance, it is the combination of art, sport and sports performance (Riding, Wyon, Ambegaonkar, \& Redding, 2013). This sport is composed of three forms: Latin, Standard and Ten Dances (WDSF, 2012a). The combination of both modalities ends in another discipline known as 10 dances and it would be the most complete modality (Cantón \& Checa, 2011). In Spain there are different categories, depending on the level (FEBD, 2013). The national categories in Spain are C, B, A, being A the highest national category and the international category: A international (FDBDV, 2015). In the DanceSport, we can emphasize two relevant components: Aesthetic component and the physical component (Chren, Spanik, \& Kyselovicová, 2010). The five Latin dances are Samba, Cha-Cha-Cha, Rumba, Paso Doble and Jive (WDSF, 2012b) that differ between in rhythm and tempo. For obtaining satisfactory sports results the development of motor skills is necessary, being this object of the sports training, as well as physiological adjustments result of the realized training, to anticipate injuries (Uzunović, 2008). As Kruusamäe et al. (2015) indicate, the sportsmen and women dancers acquire certain positions, causing permanent anatomical changes. Physiological adjustments result from the realized training, to anticipate injuries (Liiv et al., 2014; Zanchini \& Malaguti, 2014). Vaczi et al. (2016) points out that women get more energy expenditure than men during the competitive development of sports dancing, and notes that this is given by the technique. Liiv, Jurimae, klonova, \& Cicchella (2013) also notes that the woman reaches higher heart rates in the different dances. The goal of this study is analysed the muscles during the development of the choreography in the rhythm of Latin, named Rumba Bolero. Was chosen given that it has a measure of $4 / 4$ and 25 or 27 measures per minute, that is to say movements slower and maintained than in the rest of the rhythms.

\section{MATERIALS AND METHODS}

\section{Participants}

The sample consisted of 8 couples of dancers (16 participants; $20.50 \pm 2.75$ years) of category A. Inclusion criteria: be active competing in DanceSport, belong to category $A$ and be in the group Adult I. Participants in the study had to remain 24 hours prior to the realization of the measurements without physical activity.

\section{Procedures}

The measurements were carried out by means of electromyography of surface (EMGs). The muscles measured in the study in both genres were: Rectus Femoris (RF), Biceps Femoris (BF), Tibialis Anterior (TA) and Gastrocnemius Medialis (GE). The measurements were carried out in two sessions, with a difference of $24 \mathrm{~h}$. In the first session they realized a warming and later we measured the Maximum Voluntary Isometric Contraction (MVIC) and realized the familiarization with the choreography. In the second session, first they realized a warming and later we measured the muscular activation according to the rhythm. The choreography chosen of Rumba for the measurements, was the following one: Basic Movement; Alemana; Check from open Counter Promenade Position (CPP); Check from open CPP.

\section{Data analysis}

All the EMGs measurements were gathered with the program Megawin 3.1 (Mega ElectronicsLtd, Kuopio, Finland), they were transferred to an extension file ASC, to analyse them with Matlab R2013. Extracting in this way the Root Mean Square (RMS). All analysis was performed by means of the program SPSS Statistics v. 22.0. On the statistical analysis the test of normality was realized. Once verified the normality, the 
descriptive ones were extracted representing, the percentage of muscular activation with regard to the MVIC, the average, standard diversion and were performed Pearson Correlation between variables.

\section{RESULTS}

The obtained percentages of activation: GE with a $59.88 \%$, followed by BF with a $15.14 \%$, TA with a $13.49 \%$ and lastly, RF with a $12.68 \%$. The gastrocnemius was the muscle with the higher activation.

In Table 1, we can observe as the correlation between the MVIC of BF and RF they are significant $(p=.001)$, for what we can indicate that the sample, and in general the dancers have optimal muscular balance between RF and BF.

Table 1. MVIC in both genders

\begin{tabular}{lcccc}
\hline & MVIC RF & MVIC BF & MVIC TA & MVIC GE \\
\hline MVIC RF & & $.768^{* *}$ & .138 & .455 \\
MVIC BF & & & .112 & .123 \\
MVIC TA & & & & .90 \\
MVIC GE & & & \\
\hline
\end{tabular}

Note: $\left({ }^{*}\right)$ The correlation is significant in the level $.05 .\left({ }^{* *}\right)$ The correlation is significant in the level .01.

In Table 2, we can see that the Pearson correlation is significant for the percentage of activation between RF and GE $(p=.033)$, and also for BF and TA $(p=.030)$.

Table 2. Percentage of Activation in both genders

\begin{tabular}{lcccc}
\hline & Percentage RF & Percentage BF & Percentage TA & Percentage GE \\
\hline Percentage RF & .337 & .061 & $.534^{*}$ \\
Percentage BF & & $.541^{*}$ & .248 \\
Percentage TA & & & .026 \\
Percentage GE & & & \\
\hline
\end{tabular}

Note: $\left({ }^{*}\right)$ The correlation is significant in the level $.05 .\left({ }^{* *}\right)$ The correlation is significant in the level .01.

In Table 3, correlations between MVIC for activation among muscles, for women is significant the correlation between RF and BF ( $p=.003)$ and then the correlation among RF versus GE $(p=.002)$. 
Table 3. MVIC for women

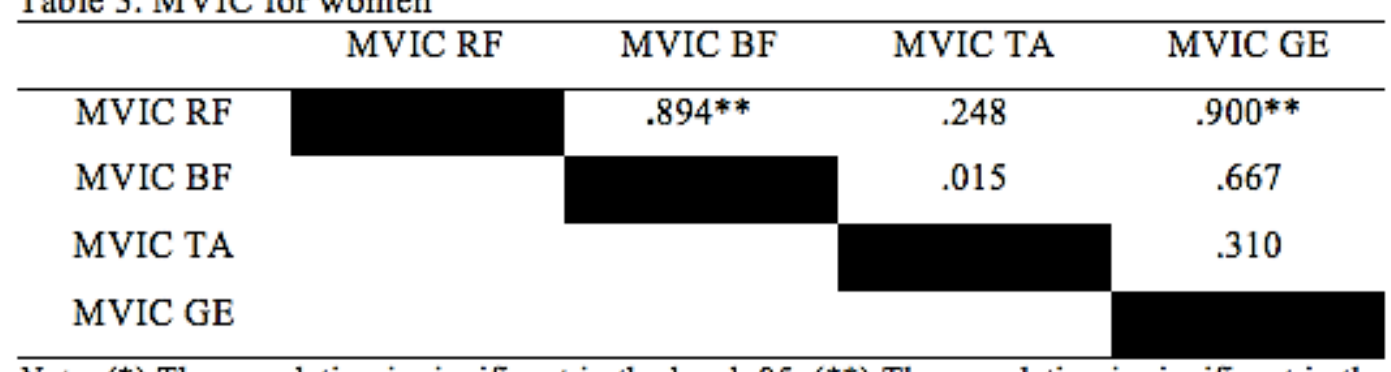

Note: $\left({ }^{*}\right)$ The correlation is significant in the level $.05 .\left({ }^{* *}\right)$ The correlation is significant in the level .01.

In Table 4, with regard to the percentages of activation in women, we can emphasize as significantly the correlation of the activation percentages among RF and GE $(p=.011)$. And then the positive correlation of activation in the percentages of TA and GE $(p=.050)$ in Rumba.

Table 4. Percentages of Activation Between Muscles in Women

\begin{tabular}{l|cccc}
\hline & Percentage RF & Percentage BF & Percentage TA & Percentage GE \\
\hline Percentage RF & & .507 & .368 & $.828^{*}$ \\
Percentage BF & & & .667 & .686 \\
Percentage TA & & & $.708^{*}$ \\
Percentage GE & & & \\
\hline
\end{tabular}

Note: $\left({ }^{*}\right)$ The correlation is significant in the level $.05 .\left(^{* *}\right)$ The correlation is significant in the level .001 .

Pearson's correlations are not significant for men in any of the three analyses: MVIC, activation averages and activation percentages.

\section{DISCUSSION}

DanceSport is a minority sport therefore the studies realized in this sport are limited. The particularity of the study, it was the analysis of the choreography of Rumba Bolero to the couples in movement, by means of the EMGs. We should note that the studies, performed with electromyography of surface in dancers are almost non-existent.

The gastrocnemius medialis (GE) was the muscle with major activation, it can owe, to the use of shoes heel, in both genders (Zagorc, Šimunič, Pišot, \& Oreb, 2010).

In the correlations between kinds we have only found significant results in the group of women. As indicates Zagorc et al. (2010), this would have relation with the employment of the heel, provided that the ballerinas use a much higher heel and must compensate to have the anticipated weight, with the aim to execute better the technique. This could also be determinant since studies like Liiv et al. (2013) and Vaczi et al. (2016) indicate that women get to have greater energetic and cardiac expenditure than the men in the course of the competition, reason why could also be related to a significant muscular activation in the women. 
The correlation between the MVIC in both genders of RF and BF we observe a balance between muscles agonists and antagonists, and then in the correlation of percentages of activation between BF and TA, for what we indicate that the dancers generally, would be well-balanced muscles in general. This would be a good indicator of the toning of the dancers since the reduction of the strength would be associated with the appearance of the injuries (Malkogeorgos et al., 2013).

We will continue investigating in this line in the rest of dances, to be able like that to see also the differences between these. Since in the modality of Rumba Bolero if we have found differences between genders.

\section{CONCLUSIONS}

Taking into account the results obtained from muscle activation, it is possible to observe the differences. Women have significant differences and therefore greater activation and energy expenditure, thus additional work should be done on the lower train to boost strength, prevent injuries and maintain the high level of demand.

\section{REFERENCES}

1. Cantón, E., \& Checa, I. (2011). Entrenamiento psicológico en baile deportivo y de competición. Revista de Psicología Del Deporte, 20(2), 479-490.

2. Chren, M., Spanik, M., \& Kyselovicová, O. 'ga. (2010). Blood lactate concentration of ballroom dancers according to the length of their routines. Acta Facultatis Educationis Phsicae Universitatis Comenianae, 50(2), 43-50.

3. FDBDV. (2015). Tipos de competiciones. Grupos de edades. Categorías y promoción. Retrieved 20 May 2015, from http://www.fbdcv.com/tipos-de-competiciones-grupos-de-edadescategor\%C3\%AD-y-promoci\%C3\%B3n

4. FEBD. (2013). Federación Española de Baile Deportivo. Retrieved from http://www.febd.es/es/menu-principal/la-aebd/id/9

5. Kruusamäe, H., Maasalu, K., Wyon, M., Jürimäe, T., Mäestu, J., Mooses, M., \& Jürimäe, J. (2015). Spinal posture in different DanceSport dance styles compared with track and field athletes. Medicina, 51(5), 307-311. https://doi.org/10.1016/j.medici.2015.08.003

6. Liiv, H., Jurimae, T., klonova, A., \& Cicchella, A. (2013). Performance and Recovery Stress Profiles in Professional Ballroom Dancers, Medical Problems of Performing Artists, 28(2), 65-69.

7. Liiv, H., Jürimäe, T., Mäestu, J., Purge, P., Hannus, A., \& Jürimäe, J. (2014). Physiological characteristics of elite dancers of different dance styles. European Journal of Sport Science, 14, S429-S436. https://doi.org/10.1080/17461391.2012.711861

8. Malkogeorgos, A., Zaggelidou, E., Zaggelidis, G., \& Christos, G. (2013). Physiological Elements Required by Dancers. Sport Science Review, XXII(5-6). https://doi.org/10.2478/ssr-2013-0017

9. Riding, T., Wyon, M., Ambegaonkar, J., \& Redding, E. (2013). A Bibliographic Review of Medicine and Science Research in DanceSport. Medical Problems of Performing Artists, 28(2), 70-79.

10. Uzunović, S. (2008). The transformation of strength, speed and coordination under the influence os sport dancing. Physical Education and Sport, 6(2), 135-146.

11. Vaczi, M., Tekus, E., Atlasz, T., Cselko, A., Pinter, G., Balatincz, D., ... Wilhelm, M. (2016). Ballroom dancing is more intensive for the female partners due to their unique hold technique. Physiology International, 103(3), 392-401. https://doi.org/10.1556/2060.103.2016.3.11

12. WDSF. (2012a). World Dance Sport Federation. Retrieved from http://www.worlddancesport.org/about 
13. WDSF. (2012b). World Dance Sport Federation. Retrieved from http://www.worlddancesport.org/About/Dance\%20Styles/Latin_\&_Standard

14. Zagorc, M., Šimunič, B., Pišot, R., \& Oreb, G. (2010). A comparison of contractile parameters among twelve skeletal muscles of inter-dance couples. Kinesiologia Slovenica, 16(3), 57-65.

15. Zanchini, A., \& Malaguti, M. (2014). Energy requirements in top-level DanceSport athletes. Journal of Human Sport \& Exercise, 9(1), 148-156. https://doi.org/10.4100/jhse.2014.91.15 